Kyle R. Brady*

\title{
Comprehensive Homeland Security: Developing a Domestic Protection Force for the United States
}

DOI 10.1515/jhsem-2016-0012

\begin{abstract}
The ideation and execution of American homeland security has substantially evolved over the past fifteen years from a vague statement of principles to a very concrete, professional, and institutionalized field, with a cabinet-level department associated with various aspects of its practice. However, homeland security in the United States - defined as the protection of citizens, property, and interests beginning at international borders and expanding inward - is not yet fully developed or even secure in its own roles. As the evolution of both the theory and the practice continues, an important principle - analogous to one in the field of national security - must be sufficiently addressed and acted upon: the physical act of protecting sovereign territory.
\end{abstract}

Keywords: counterterrorism; Department of Homeland Security; force protection; homeland security; law enforcement; terrorism.

\section{Comprehensive Homeland Security: Foundation}

Homeland security, as both a term and an actual theater of interest, did not fully exist prior to the terror attacks of September 11, 2001; however, the concept and practice were quickly thrown into being by President George W. Bush in the days, weeks, and months that followed (see Reese 2013; DHS 2015). Although initially a somewhat vague subset of national security, American homeland security has come to be defined as the domestic theater of concern, with an interest in deterring, detecting, preventing, mitigating, and responding to sizeable incidents that harm the nation, its people, and its fabric at or within its own borders (Brady 2015b). In academic terms, homeland security very often means preparation for,

*Corresponding author: Kyle R. Brady, Masters in Homeland Security, Pennsylvania State University, PA, USA, e-mail: brady.k@gmail.com 
prevention of, and response to both terrorism and all-hazard incidents, the direct outgrowth of a fusion of emergency management, security studies, and public administration programs.

As such, homeland security is clearly distinct from national security: the former protects the American people and their interests domestically while the latter seeks to do so abroad. Similarly, the Department of Homeland Security (DHS) is tasked with domestic protection and prevention efforts, including at the nation's borders, while foreign efforts are largely split between the Department of Defense, militarily, and the Department of State, diplomatically. Supporting efforts in homeland security are provided by various domestic-facing federal law enforcement agencies and constitutionally limited intelligence agencies, while a comparably larger variety of intelligence agencies and notably fewer law enforcement agencies operate in the field of national security.

The Constitution, its amendments, and the body of law in the United States, however, present a difficult problem for domestic protection and prevention efforts: not only can the military not be used domestically, ${ }^{1}$ but there are also strict limitations on the ways in which intelligence may be both collected and used. ${ }^{2}$ Consequently, the domestic theater in which homeland security inherently operates, by its very definition, restricts the abilities of the federal government to carry out its mission to secure the safety of its people within its borders. The result, as is often noted, is a department that stands as a patchwork of the interests, missions, and jurisdictions of its constituent components.

Although border security (Brady 2015b), transportation infrastructure (Brady 2014c), and cybersecurity (Brady 2014a) are all critical areas of need, the United States faces an even greater threat - despite the best efforts of both the law enforcement (Brady 2015c) and the intelligence (Brady 2015a) communities - in the inevitable inconsistencies and gaps across the country that are the natural result of having no single, unified entity responsible for homeland security prevention, protection, and response efforts. An extraordinary amount of funding and effort has been expended in retraining and equipping state, local, tribal, and territorial (SLTT) governments and law enforcement agencies to address homeland security issues (FEMA 2015), ${ }^{3}$ but this is an expensive patchwork effort restricted by traditional thinking and the inherent limitations of those entities being relied upon.

\footnotetext{
1 Except in extreme cases and in very limited ways, such as for national disasters, states of emergency, supporting law enforcement, and defending against actual invasion.

2 As outlined by the various acts, executive orders, and case law pertaining to intelligence collection activities, particularly since late 2001.

3 The dollar value of FEMA's Homeland Security Grant Program - merely one facet of SLTT homeland security expenditures - exceeds US $\$ 1$ billion.
} 
In the event of a major homeland security event, whether a large-scale terror attack, a number of small-scale terror attacks carried out in parallel, or even the proliferation of extreme violence related to foreign drug cartels, the first responders will invariably be SLTT members whose training and focus may have been in fields other than homeland security, resulting in a squandered opportunity in those very important first moments. Moreover, undertaking actions designed to prevent - not just deter - undesirable and premeditated acts of terror in the American homeland is very often outside the scope of expectation, much less ability, of SLTTs. ${ }^{4}$ Therefore, an improved and more dedicated solution must be devised.

\section{Comprehensive Homeland Security: Creation}

To better address the needs of homeland security, universally if not uniformly, the federal government must seek an improved model for prevention, protection, and response. Moreover, it must find a method to achieve necessary homeland security missions and goals without compromising other aspects of the American way of life. If effective and preventive homeland security, or even the general domestic security of the nation, is to remain a goal of the United States, more effort must be applied to not just its study but also its application. The field is one to which reactive measures and endless bureaucracy seem prone, with duplicative organizations, wasted funding, and substantial SLTT mission creep. If a more universal homeland security organization were to be created in a way that addresses substantial security concerns, flaws, and deficiencies while simultaneously reducing jurisdictional overlap, duplication of effort, mission confusion, and bureaucratic layering, then the complexity of such an undertaking would be both understandable and justifiable.

Any reorganization of the national homeland security effort must reflect a universal improvement; otherwise, the undertaking would be meaningless. Therefore, it must be a carefully planned federal effort so as to avoid the continued quagmire that has resulted from the creation of DHS in the aftermath of September 11, 2001. A substantial amount of forethought must be placed in deciding how to encapsulate the mission areas of homeland security within a single, integrated organization that includes the four central areas of effort - protection, investigation, intelligence, and administration - in a way that produces results better than the sum of all its parts. Moreover, the resultant organization must be

4 A majority of SLTT law enforcement agencies have a primary focus on local law enforcement, community policing, crime prevention, and traffic enforcement. 
founded largely out of the preexisting governmental entities strewn across the government. Fortunately, a model of best fit for these requirements has had more than two centuries to develop and hone every aspect of its being while becoming exceedingly proficient in all its assigned duties: the US Armed Forces.

As the world's preeminent and most advanced military, ${ }^{5}$ the US Armed Forces has extraordinary abilities in a variety of fields, such as training and self-perpetuation, logistics, infrastructure, transportation, resource deployment, and, of course, warfighting. The American military, therefore, stands as the model for everything that modern homeland security requires. However, since the armed forces cannot be used domestically (except in the very limited situations previously noted), a homeland security protection force (HSPF) must be developed using the military as its well-developed guide (Brady 2014b, 2015e). ${ }^{6}$

An HSPF would need to be created statutorily, with a mandate to protect the American government, territory, people, and interests at and within its borders, in accordance with all constitutional and legal requirements, in order to deter, detect, prevent, mitigate, and respond to sizeable incidents. Although modeled after the US military, the HSPF would receive no military designation; operating strictly within American borders, it would be a sizeable and semi-independent component of DHS with a fusion of law enforcement, intelligence, and security designations. It would absorb the National Guard and supplant many of the SLTT homeland security efforts, freeing the latter for traditional SLTT law enforcement concerns. The US Coast Guard (USCG), transportation security administration (TSA), ${ }^{7}$ National Park Service Rangers and Special Agents, US Park Police, US Secret Service-Uniformed Division, US Capitol Police, Federal Protective Service, Bureau of Alcohol Tobacco, Firearms, and Explosives (ATF), Homeland Security Investigations, and Federal Emergency Management Agency (FEMA) would be all absorbed or transferred into the HSPF, while traditional border security activities would remain distinctly separate from it. ${ }^{8}$ The personnel protection details

5 At least in terms of common beliefs, the demonstrable lack of a competent challenging force, and President Obama's 2016 State of the Union Address (New York Times 2016).

6 This concept was previously explored briefly in the two cited blog posts: as the beginning of an HSPF theory (2014b) and as an initial theorization of how current law enforcement and intelligence structures might be reorganized to produce a result similar to a protection force within common structures (2015e).

7 Much of the TSA's workforce would be reallocated to other DHS components or discharged. This is the result of more than a decade of poor hiring practices, low personnel performance, and an agency culture not conducive to the mission of the proposed HSPF. See Halsey (2015) for further details.

8 However, border security itself needs to be streamlined and unified into a single agency with clarified jurisdiction, mission, and authority; see Brady (2015d). 
of department-specific Special Agents would be transferred to the HSPF, along with all such personnel, as would all federal police departments, agencies, and officers. ${ }^{9}$ All domestic-facing intelligence agencies or efforts with law enforcement interests would also be absorbed or transferred into the HSPF. ${ }^{10}$ Any and all contracts with private sector entities to provide physical protection of federal facilities or personnel would be canceled, with these responsibilities - including personnel, equipment, properties, physical assets, and budgets - fully transferred to the HSPF. Current homeland security SLTT grants would be decreased in direct proportion to the increased homeland security responsibilities of the federal government, as extraordinary and expanded SLTT law enforcement and intelligence efforts are reduced to more traditional levels.

To properly execute its mission, the HSPF would be divided into five directorates: Administration, Protection, Response, Investigations, and Intelligence. The Directorate of Administration would be responsible for all nonfield/nonintelligence activities, with no law enforcement, security, or intelligence component. The Directorate of Protection would have law enforcement/security designation and be responsible for physical (the Office of Assets) and personnel (the Office of Personnel) asset protection of federal buildings, property, and personnel, as well as national parks, landmarks, and events or locations of national significance. The Directorate of Response would have law enforcement/security designation and be responsible for executing actions to prevent, interdict, and mitigate threats to the homeland, sourced in terrorism of any kind (the Office of Counterterrorism) and all-hazards (the Office of Hazards). The Directorate of Investigations would have law enforcement designation and be responsible for any investigations - criminal, internal, or otherwise - related to the efforts of the HSPF. The Directorate of Intelligence would be strictly an intelligence operation with a domestic focus but universal jurisdiction, responsible for collecting and assessing intelligence related to homeland security for use by the Protection, Response, and Investigations Directorates.

Furthermore, the HSPF would use the dual-track hierarchical rank system of the military, with a general in charge of the force itself and a lieutenant general for each directorate. Although the HSPF general would report directly to the secretary of DHS, the position would also be made a permanent member of the National Security Council as the homeland security advisor. Except for those

9 Except for the domestic, force protection police forces of nonabsorbed intelligence agencies and national security entities.

10 This, of course, excludes the Federal Bureau of Investigation (FBI), Drug Enforcement Administration, Central Intelligence Agency, National Security Agency, and any intelligence efforts both wholly or partially owned - of the Department of State or Department of Defense. 
officers individually assessed and approved for transfer from prior agencies or contracts at the time of the HSPF's formation, officers would be required to hold a graduate degree or have Superior Academic Achievement in their undergraduate education; enlisted personnel would be required to hold a minimum of an associate's degree.

As a national protection force, the HSPF would operate bases in every state and have smaller satellite bases near every major American city for quick and responsive deployment. ${ }^{11}$ To this end, it would require the full complement of air, land, and sea vehicles at every base, along with the trained personnel to staff them. ${ }^{12}$ Additionally, it would have rapid response teams (RRTs; also known as SWAT, emergency response teams, or counterterrorism teams) stationed at every base, ready to respond to a variety of incidents requiring their skill sets. Responsibility for Joint Terrorism Task Forces would transfer from other agencies to the HSPF, where these efforts would continue and be cultivated as a significant asset.

Training for all members of HSPF would employ the military's use of basic and job-specific advanced/technical training, combined with current best practices found in the law enforcement training programs at the various Federal Law Enforcement Training Center (FLETC) locations. This would permit all of the HSPF to have a unified mission and purpose, as well as a universal understanding of the organization's structure, while simultaneously cultivating individual specializations. To undertake such a massive and continuous training effort, the FLETC bases in New Mexico and South Carolina, which are currently not being fully used for law enforcement training, would be transferred to the HSPF and developed into large-scale, permanent training facilities for all aspects of the force.

As a domestic-facing protection force, the HSPF would have to carefully develop a use-of-force policy for the continuum of force-based responses possible in any interaction in which it was involved. So, too, would it have to develop specific rules of engagement. Both sets of policies would have to give the HSPF broad latitude to undertake any and all efforts necessary to protect homeland security, in all its forms, while simultaneously ensuring that the rights of all law-abiding American citizens are protected. Moreover, they would have to acknowledge that the mere presence of the HSPF could, in many circumstances, escalate a situation.

11 Much of this widespread, base-oriented structure can be provided by using preexisting $\mathrm{Na}$ tional Guard resources absorbed by the HSPF.

12 As with bases, much of the equipment required would be accessible through the absorption of the National Guard. 
This, then, requires a nuanced understanding of the interests, needs, and rights of the American people in order to avoid unnecessary violence and harm while simultaneously maximizing the utility of the force. Ultimately, however, the HSPF would not be bound by a separate code, as is the military by the Uniformed Code of Military Justice; rather, it would be governed by the Code of Federal Regulations and US Code; by relevant statutes, laws, regulations, and ordinances (within the context of the Supremacy Clause); by related executive orders; by DHS policies and regulations; and by its own policies, regulations, and procedures.

The creation of the HSPF would also have to address overlapping jurisdictions and all associated concerns. The organization would have primary jurisdiction in all protective, reactive, and intelligence aspects of homeland security, regardless of particular geographical location, the desires of other federal agencies, or SLTT concerns. ${ }^{13}$ Investigational jurisdiction would be both primary and shared: depending on the circumstances of an investigation, another federal agency would be able to conduct the investigation jointly with the HSPF. In counterterrorism efforts, including SWAT and RRT scenarios, the HSPF would maintain lead authority but may choose to request backup or supporting efforts from relevant federal agencies. Additionally, the current primary jurisdictions of all absorbed entities would also become part of the HSPF's primary jurisdiction. As a premiere federal agency, the HSPF would override any SLTT jurisdictional or investigative authorities with regard to homeland security concerns.

\section{Comprehensive Homeland Security: Criticism}

Inevitably, the ideation and instantiation of an organization as large, sweeping, and effective as the HSPF would have vociferous critics of all kinds, including members of Congress, affected departments and agencies, SLTT governments and law enforcement personnel, civil liberties advocates, political libertarians, and certain sectors of both liberal and conservative politics. This, however, does not mean that the HSPF is any less necessary or important to create. The anticipated concerns must be carefully and succinctly addressed preemptively in order to avoid a misunderstanding of the HSPF's mission and duties.

13 This would remove some of the past decade's counterterrorism burden from agencies such as the FBI and ATF, allowing them to refocus on their core efforts rather than requiring a substantial division of both attention and effort. 


\subsection{A Domestic Military}

The United States has a long history of preventing the use of the armed forces within its own borders, and the first criticism imaginable against the formation of the HSPF would be that it is essentially a domestic military. However, this is simply not true, as the authorities and jurisdictions provided clearly outline the HSPF as encompassing law enforcement, security, intelligence, and other homeland security-related functions, none of which are those of the military or even militaristic in nature. Moreover, as both the USCG (currently a DHS component) and the National Guard, in all aspects, would be absorbed in the creation of the HSPF, this organization would be acquiring resources and authorities from organizations already practicing domestic homeland security functions as a primary mission, despite foundational roots in the military and state militias. Accordingly, the HSPF could be defined and viewed as a fusion of law enforcement, security, intelligence, homeland security, and the state militias combined into a single, cohesive unit. It is, in no way, a true military force and cannot be described, derided, or decried as such.

\subsection{Infringing upon States' Rights}

The second-most expected criticism of the HSPF would be regarding the delineation between federal authorities and states' rights. This criticism is often levied at the federal government when expanded authorities are being sought, particularly in the creation of new policy. However, as already explained, the HSPF would be a unification of the various related and interrelated departments, agencies, and other organizations into a single, streamlined entity with an increased ability to execute its duties. This, then, is not an expansion of powers - and therefore also not an infringement of states' rights - but a consolidation of preexisting, tested, and accepted federal powers. While this argument against the HSPF may garner visceral support, it is without merit.

\subsection{Infringing upon Civil Rights and Liberties}

Civil rights and so-called civil liberties have gained increased prominence in public discussions over recent decades, so it would seem inevitable that this line of attack on the HSPF would be used. But again, the HSPF would be formed out of preexisting entities with prior authorizations, jurisdictions, and powers: if such an organization could be considered infringing upon civil rights and liberties, 
its relevant predecessors would also be liable to similar complaints. It should be noted, however, that the accusation of such violations is not cause for assumed guilt; rather, alleged violations of civil rights and liberties would have to be substantiated, evidenced, and defended. There are many varied definitions of civil rights and liberties, particularly in the mind of the public and certain political actors, but not all of them have valid legal standing.

\subsection{Law Enforcement and the Public}

In the current sociopolitical climate, the public - in tandem with the media - has taken a decidedly antigovernment, antilaw enforcement, and antiauthority tone. Given that this is, in many cases, a result of the disparity between the Supreme Court's use-of-force standards and the expectations of the public, such an unsupportive and combative approach to public safety providers is both noted and cautioned against overstatement. Although the HSPF will inevitably be criticized in the execution of its duties and the application of its policies, such criticism will face the same standards of validity that the Supreme Court, departments, and agencies currently apply until such time as these standards are changed statutorily or through legal precedent.

\subsection{Budgets and Associated Costs}

As they were with the creation of DHS, both Congress and the public are likely to be concerned with proposed budgets and costs associated with the reformation of existing entities into the HSPF. However, besides minimal initial administrative costs, the HSPF budget is expected to be similar to the sum of all the budgets of its absorbed components. In fact, given the ability to significantly streamline administrative and human resources expenses - including the hiring and training of its nonadministrative directorates ${ }^{14}$ - the budget of HSPF may be comparatively smaller.

14 Hiring individuals for federal security, law enforcement, and intelligence positions often requires substantial effort and cost given the many aspects of the process, including multiple interviews, a background and suitability investigation, a polygraph, physical fitness tests, a medical exam, and screening for illegal drug usage. 


\section{Conclusion}

Ultimately, the current mix of homeland security agencies and organizations, only some of which are DHS components, will continue to produce varied and problematic results - particularly within the areas of protection, prevention, investigations and intelligence - until these efforts are unified into a more coherent and cohesive whole. In creating the HSPF, nearly all of the current entities involved in such activities would not only be brought under the jurisdiction of a single department but also streamlined into a single agency. The result would unravel some of the complexity, redundancy, and inefficiency of DHS while simultaneously improving and advancing the nation's security through a better trained and more prepared force of advanced, educated, and professional individuals. By eliminating some of the current paycheck-seeking activities and instead creating a structure designed for full and well-developed careers, the HSPF could better serve the American public through both its simple existence and the public service opportunities provided. It would, in short, require little more resources than are already allocated; these resources would, however, be better used and the mission more fully and successfully executed.

\section{References}

Brady, K. R. (2014a) "The Digital Age and the United States of America: A Pervasive Cybersecurity Threat.” https://www.academia.edu/7216345/.

Brady, K. R. (2014b) "The Persistent Threat to American Transportation Infrastructure: An Unaddressed Homeland Security Issue." https://www.academia.edu/7443119/.

Brady, K. R. 2014c. "In Brief: DOD, DHS, and a Homeland Security Force." Sense and Security (blog), November 12. http://blog.kyle-brady.com/2014/11/in-brief-dod-dhs-andhomeland-security.html.

Brady, K. R. (2015a) “Better Integrating American Intelligence Agencies and Products: Revising a Recurring Solution for a Recurring Problem.” https://www.academia.edu/10792298/.

Brady, K. R. (2015b) "Secure Management of American Borders in the Modern Era: Developing an Evolving Strategy." https://www.academia.edu/11928471/.

Brady, K. R. (2015c) "The Role of Federal Law Enforcement in Preventing Terrorism and Enhancing Security.” https://www.academia.edu/11554707/.

Brady, K. R. (2015d) “In Brief: Redefining Homeland Security.” Sense and Security (blog), February 25. http://blog.kyle-brady.com/2015/02/in-brief-redefining-homeland-security. html.

Brady, K. R. (2015e) “Theorizing a Federal Law Enforcement and Intelligence Community Reorganization," Sense and Security (blog), February 5. http://blog.kyle-brady.com/2015/02/ theorizing-federal-law-enforcement-and.html. 
Department of Homeland Security (DHS). 2015. "Creation of the Department of Homeland Security." Last published September 24. http://www.dhs.gov/creation-departmenthomeland-security.

Federal Emergency Management Agency (FEMA). 2015. "Fiscal Year 2015 Homeland Security Grant Program." Last updated July 28. https://www.fema.gov/fiscal-year-2015-homelandsecurity-grant-program.

Halsey III, A. (2015) “Homeland Security Looks for Leaker of Report on Airport-Checkpoint Failures. The Washington Post, June 9. https://www.washingtonpost.com/local/ trafficandcommuting/homeland-security-looking-for-leaker-of-report-on-airportcheckpoint-failures/2015/06/09/570ede22-0eb3-11e5-adec-e82f8395c032_story.html.

“Highlights of President Obama's 2016 State of the Union Address.” 2016. New York Times, January 12. http://www.nytimes.com/interactive/projects/cp/politics/sotu-2016/ obama-praises-americas-military-strength.

Reese, S. (2013) Defining Homeland Security: Analysis and Congressional Considerations (CRS Report for Congress). Congressional Research Service. https://fas.org/sgp/crs/homesec/ R42462.pdf.

\section{Bionote}

\section{Kyle R. Brady}

Masters in Homeland Security, Pennsylvania State University, PA, USA brady.k@gmail.com

Kyle R. Brady holds a Masters in Homeland Security from Pennsylvania State University and has primary interests in terrorism, law enforcement, and placing American homeland security needs within a broader, international context. Previously, he graduated with Departmental Honors from San Jose State University's undergraduate Political Science program, where he focused on both international relations and political theory. As a proponent of open academic publishing, all of Kyle's work can be found online at http://pennstate.academia.edu/ KyleRBrady and http://docs.kyle-brady.com; he can be reached by email at brady.k@gmail.com or, nominally, on Twitter as @KyleBradyOnline; and he occasionally blogs at Sense and Security (http://blog.kyle-brady.com). 